\title{
"Quantum Governance of Development": prolegomena for a general theory and the case of an enterprise
}

by

Francesco Zanotti

f.zanotti@cse-crescendo.com francesco.zanotti@gmail.com

\begin{abstract}
Starting form a profound commitment to social responsibility, first of all, I illustrate the first draft of a theory of self-evolution of a Human System. The main resource, used by the actor (entrepreneur) who starts the self-evolution process of a human system, is his (or her) cognitive system. The scope of entrepreneur's cognitive system conditions the scope of the human system. The self-evolution process is a process of "impoverishment" of the cognitive system. The case of the enterprise is emblematic. I called the process of impoverishment of an enterprise: Value Life Cycle. To overcome this impoverishment (that is to govern a human system) it is necessary to improve the cognitive system of the entrepreneur. I illustrate two ways to improve the cognitive system of an entrepreneur. At the end I will try to generalize the discourse about enterprises to all kinds of human systems.
\end{abstract}

\section{Key Words}

Quantum vacuum, topological space, vector space, Value Life Cycle, business Unit, industry, self-evolution, Strategic Plan, profound existentiality, language, autopoiesis, collapse.

First of all, I would like to declare my point of view.

My point of view is not disciplinary, neither interdisciplinary or transdisciplinary. My point of view is "human": I think we, as system thinkers, have to take care of the present global crisis. 
Starting from this point of view, I think our challenge consists of developing a different understanding of the present crisis and in generating a new model of governance of human systems to escape from it.

Saying in other (and far better) words, we, as human beings, need a new governance of human systems to build a new society, ethically inspired and aesthetically superb.

The aim of this paper is to present a proposal for a new governance (a new kind of management) of human systems, first, in general terms and, then, studying a specific human system: the enterprise.

\section{Autonomous evolution of a human system: a qualitative "flavor"}

The main characteristic of a human system is a special form of emergence: an autonomous evolution.

In the specific case of an enterprise, I called this autonomous evolution "Value Life Cycle": a self-generated Value Life Cycle.

In literature there are a lot of models for describing the Life Cycle of an enterprise. But all of them share the same "epistemology": the Life Cycle of an enterprise is generated by the environment.

I think system theory suggests the opposite point of view: the Life Cycle is generated by the enterprise itself.

Let me illustrate, first of all, what this change of perspective has to do with the present crisis.

\section{To believe in Fate or in ourselves?}

The main problem of enterprises is their reduced capacity of producing value.

What are the causes of this depressing problem?

There are two alternatives.

The first one represents the point of view of the majority (totality?) of the traditional Life Cycle models: the present decreasing capacity of producing value of enterprises is caused by... Fate!

Well, no one talks explicitly in terms of Fate.

Experts discuss around a crisis which makes competition fiercer and fiercer. 
The increasing level of the competitive battle forces enterprises to invest more and more resources to increase their competitiveness.

Unfortunately, other competitors do the same. And, due to the fact that resources available to main competitors are almost similar, no competitor can hope to acquire a sustainable competitive advantage.

The final result is that crisis forces enterprises into a vicious circle, at the end of which there is the total loss of capacity of producing value.

But, what does Fate matter?

Actually, Fate is very similar to crisis: no one knows where it comes from. And, first of all, chief executives or entrepreneurs cannot, in any way, eliminate factors which generate crisis

They can manage crisis as ancient Greeks used to manage Fate: just praying.

The second alternative is represented by my point of view. And it is in no ways fatal. Instead, it is from all points of view decisive for solving the present crisis. Actually, crisis reveals that the present economic system (products and manufacturing systems, services and service procedures) is losing its meaning and its functionality. And it is increasingly conflicting with People and Nature. Competition is the inevitable result of this loss of meaning and functionality. At the same time, in almost all the "interstices" of present society a lot of "Signs of the Future Times" are emerging and indicating roads to design new economic systems.

If enterprises (CEO and entrepreneurs) do not consider "Signs of the Future Times" and they try to defend their present, these "Signs" will become threats.

Summing up competition, generated by the acceptance of loss of meaning, and "Signs" transformed into threats, force the conclusion that entrepreneurs and CEOs are the Fate of themselves. A strange Fate which enjoys damaging itself.

Once the importance of epistemological perspective has been underlined, it is necessary to find a precise model to describe, from a constructionist point of view, the process of self-evolution of a human system, in general terms, and the process of evolution of an enterprise, in specific terms. 


\section{The general evolution of a human system}

The process of self-evolution of a human system is a recursive process which repeats the same module described in the following figure.

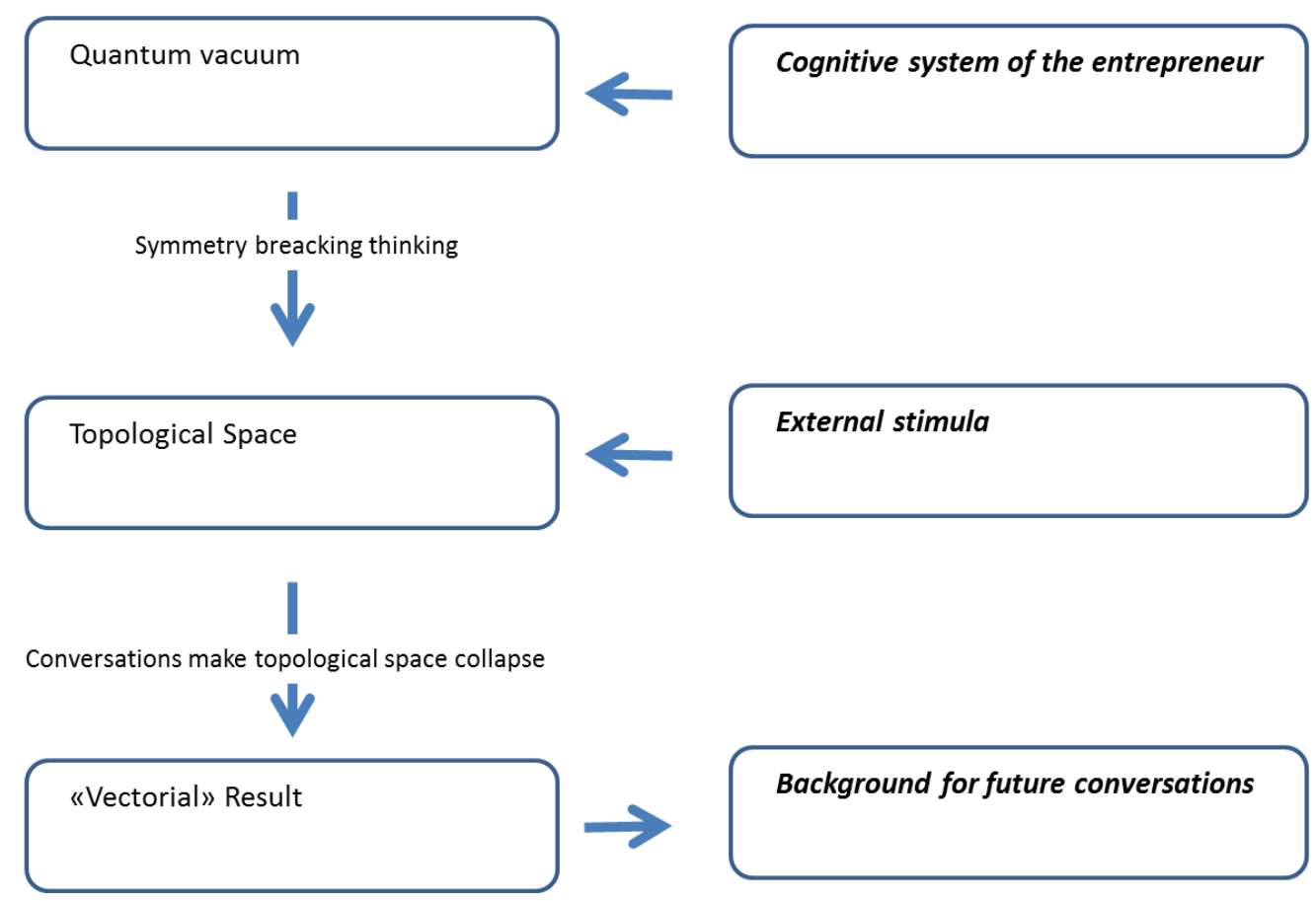

Let me describe this recursive module first in abstract terms. Then, I will actualize it in the case of self-evolution of an enterprise.

In abstract terms the starting point of every human system is the space of its profound existentiality. For all practical purposes, it can be considered "limitless". I do not use the word "infinite" because for it to make sense it would be necessary to refer to some (to be defined) metric space of infinite dimensions. I think the best model to describe profound existentialities of human systems can be the quantum vacuum.

At the very origin of every human system there is an "entrepreneur". I do not mean just an economic entrepreneur, but a systemic one. A proactive actor who makes a human system emerge and evolve. 
An entrepreneur, who is a human system too, is characterized by his (or her) cognitive system.

A cognitive system is the interface from the profound existentiality of a human being and the world. As if the profound existentiality could not stand the hardness of the world and it needed a softening ambassador. This cognitive system is something like a personal enabling tool to converse with the world. It is, at the time, the "limit and resource" for the entrepreneur.

Because of the action (the action of thinking, using his or her cognitive system) of an entrepreneur, the quantum vacuum loses its complete symmetry. The result is what I propose to call a topological space of social dreams that the entrepreneur can imagine through his (or her) cognitive system.

Why to use the topological space as model? Because of the strange nature of dreams. They permanently interact through unions and intersections. Unions and intersections of dreams are still dreams. All dreams are entangled and live outside time.

The topological space of dreams lives outside time till external stimula activate conversations, with other actors, which generate a collapse of the topological space in a vector of an environment subspace. Dreams collapse and time emerges.

\section{Stages of Value Life Cycle of an enterprise}

As I have already said, using this model, it is possible to describe the phases of self-evolution process of an enterprise due to the action of an entrepreneur.

\section{A "constant" Environment}

Following Vitiello's Theory of mind, dreamers want to see in the world a "Double" of themselves which they recognize as the realization of their dreams.

Of course this Double has to be created. So, to make a dream come true it is necessary to build a new piece of the world.

To create a piece of the world it is necessary to use ... the world. From the point of view of the entrepreneur (a traditional industrial entrepreneur) the world (the environment of the enterprise) can be seen as made by four macro parts. The 
Nature as raw material and ultimate proscenium. The media as conversation tools. The technology system and the cognitive resources of the Environment as operative enabling tools. The society (its social, political, institutional and cultural dimensions) as the context for entrepreneurial action.

\section{Simplifying Hypothesis}

In this paper I made a simplifying hypothesis. The environment of an enterprise can be modeled with a vector space which does not change over time.

Future researches will explore a more "intense" entrepreneurship. An entrepreneurship which is able to modify any proscenium. For describing this kind of entrepreneurship a reference model to describe the structure of proscenia will be necessary. Just to give some awesomeness to the reader, the macro environment might be modeled by fuzzy vector spaces and Nature (according to Gaia Hypothesis) by the same quantum topological space as for the profound existentialities of the human systems.

\section{$I^{\circ}$ Phase}

\section{Attractiveness generation}

The starting point is the profound existentiality of the present society. What this existentiality is made of? It is made of the "Signs of Future Times" which can be modeled by Quantum Vacuum.

Signs of Future Times are continuous inputs for all the phases of the selfevolution process of an enterprise. Problem is that the cognitive system of the entrepreneur becomes narrower and narrower, as the self-evolution process progresses. So Signs of Future Times always become more obscure for the entrepreneur.

The entrepreneur, using his (or her) specific cognitive system (which is a subsystem of the system of cognitive resources available in the Environment and which is unknowable) breaks the symmetry of the "Signs of Future Times" so that a topological space of social dreams emerges. Social dreams are about new possible worlds. 
External stimula act over the topological space of social dreams. External stimula are made up of "Meaning Techologies". I mean: technologies through which is possible to objectify a dream in a product with not just a functional role, but also with an existential one. By the way, in this paper I will only talk about "product", but same discourses are valid also for a service.

External stimula are made, also, of potential Clients and Suppliers

Stimula make social conversations start among the entrepreneur and the potential clients and suppliers.

Conversations act like a quantum measurement operator on social dreams of the entrepreneur.

Using the words of David Bohm (Undivided universe, pag. 6): “... after the interaction (conversations in our case) is over, the system (the social dreams in our case) enters into one of a set of channels, each of which corresponds to the possible result of measurement process. The other channels are shown to become inoperative". As if conversations reduced, transformed and interpreted the social dreams.

Conversations act like a quantum measurement operator also on individual actors who become "clients" or "suppliers".

In synthesis, conversations are, at the same time, profoundly generative and destructive.

Conversions, in this stage, are cooperative due to the fact that they are aimed at defining boundaries of a new industry.

The final result ("vectorial" because it can be modeled by a vector of a vector subspace of the environment) is the establishment of a small world consisting of:

- Well defined industry

- A noticeable attractiveness (in term of capacity of producing value)

- Specific set of Clients and Suppliers

This small world becomes the future cognitive system of the entrepreneur.

\section{All the Phases in a table}

To make long story short, I have summarized in a table the main characteristics of all the phases of the self-evolution process of an enterprise. 
In the vertical axis of the table I have put the phases of the self-evolution process.

In the horizontal axis I have put the "leading actors" of the self-evolution process.

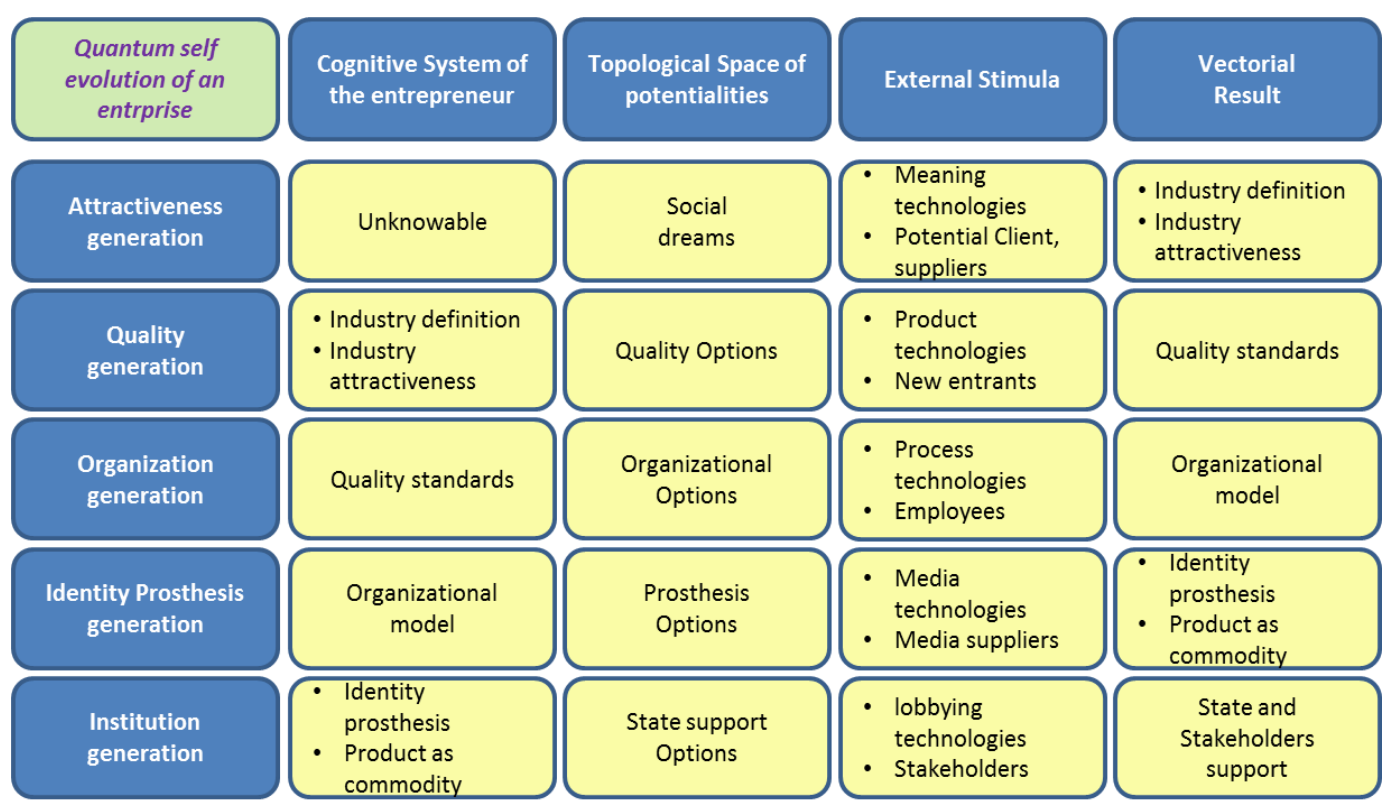

As anyone can see the recursivity is evident in the fact that the "Vectorial result" of a phase becomes the Cognitive system of the entrepreneur in the successive phase.

\section{Qualitative forecast using Value Life Cycle}

In the previous part of this article I have used the word "enterprise": an enterprise which generates an industry.

An improvement of language is necessary: instead of "enterprise" it is almost mandatory to use the concept of "Business Units" (BU).

The $B U$ is defined as a part of an enterprise which has organizational, financial and market autonomy (considering first order interactions) from the point of view of the environment.

Using BU concept we can say that an entrepreneur creates a BU which, in turn, creates a specific industry.

From now on I will use the concept of BU. 
Coming back to the main discourse, in every industry, the "zero sum games" among competitors give rise to progressively loosing meaning (for the customer-observer) for the enterprise.

Decrease of meaning means decrease of the capability to produce value at industry level.

By "value" we basically mean three "things":

$>$ Sales (at BU level)

- EBITDA (at BU level)

Cash-Flow from sales (at BU level)

By "decrease of the capability to produce value" I mean the progressive decrease in sales, EBITDA and Cash-Flow from sales.

The basic issue is that the decreasing trend is different from Sales, EBITDA and Cash flow.

Cash-Flow decreases the fastest. EBIDTA stands aside. Sales continue to grow "for a while" in spite of the decrease in both cash-flow and EBITDA.

To represent these trends I would like to use a "dual" description of the five Phase of self-evolution: a description in terms of kinds of competition.

The equivalence table for two representations is the following.

Quantum self evolution of an enterprise
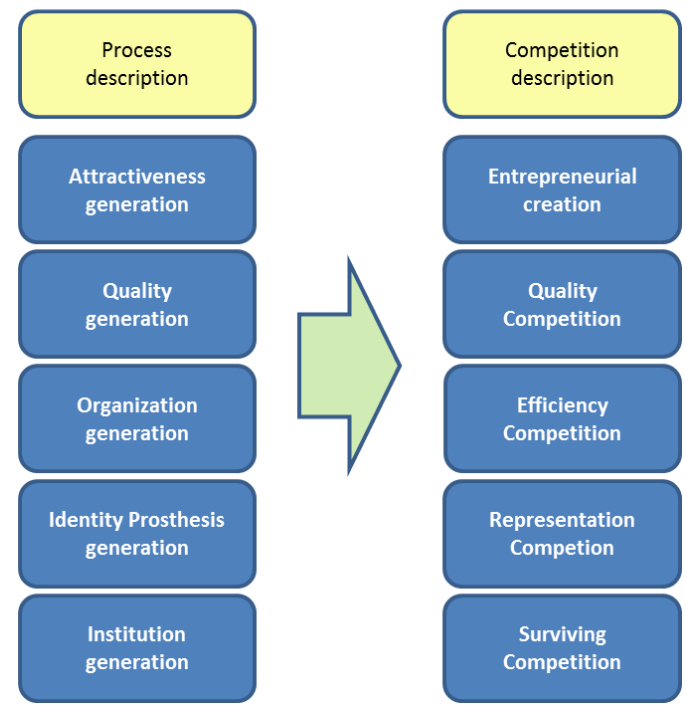
Using "Competition description", in the next figure I "qualitatively" represent the different trends in the decreasing of sales, EBITDA and cash-flow from sales (at BU level).

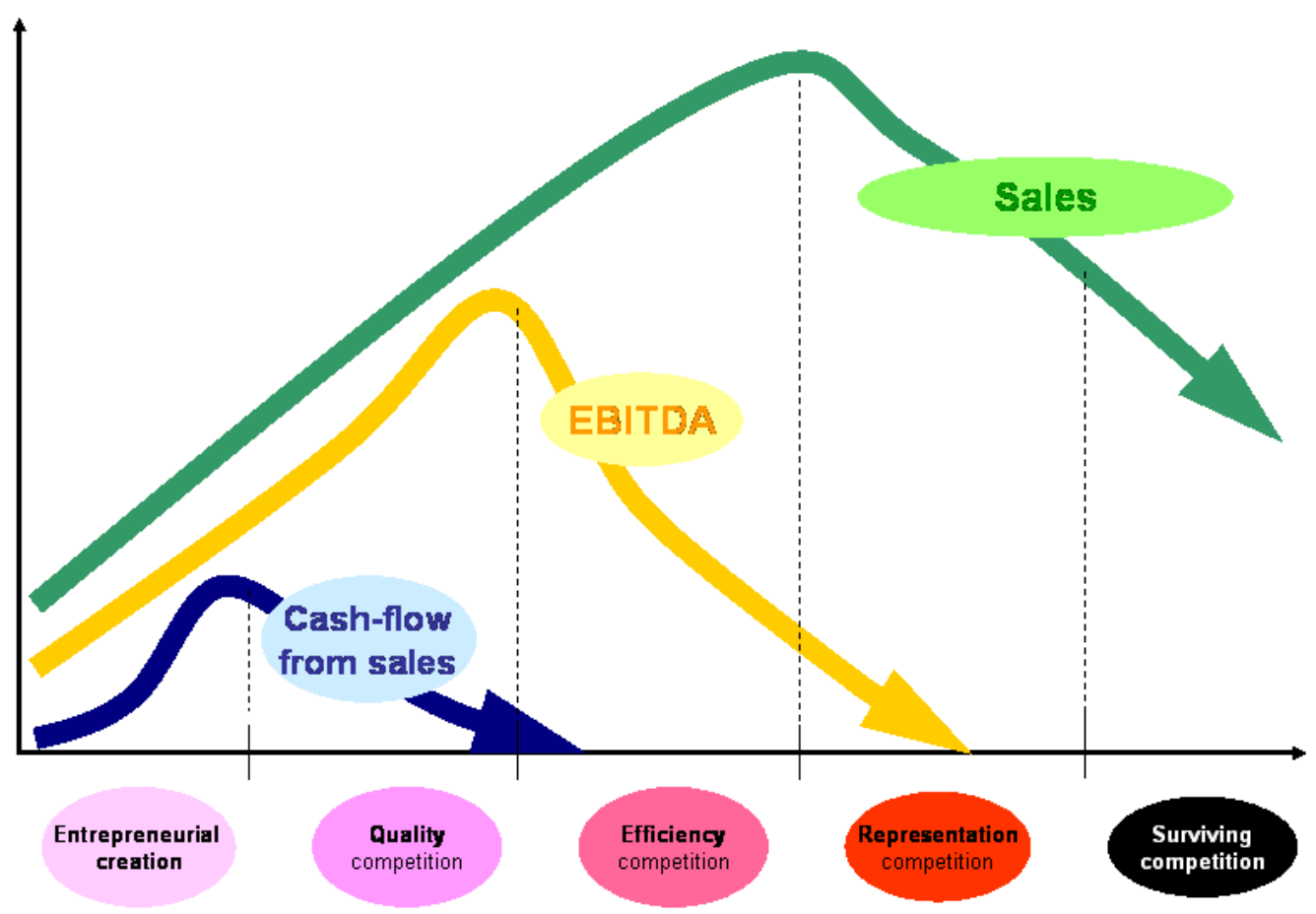

Looking at these different trends we can point out a dramatic pitfall and try to avoid it.

Managers, consultants, scholars and bankers share a static vision of competition. More precisely, they believe that only one type of competition exists. Actually, it is a mix of quality and efficiency competitions.

Taking this vision seriously means to position industries at the borderline between quality competition and efficiency competition in the above illustration. Well, in this position there is a contemporary increase in sales and decrease in cash flow generated by sales.

The result of these two opposite trends is an increase in the circulating capital. 
Where is the pitfall? It is in fact that the direct proportionality between sales and circulating capital is seen as a general law of making business while it is just the first signal of degeneration of the capability to produce value.

If you look at the previous entrepreneurial phase of the Value Life Cycle, the increase in sales corresponds to an increase in cash flow generated by sales. So, more sales means less circulating capital down to negative circulating capital. Let's consider the implications of this pitfall for bankers. Well, as they believe that an increase in sales implies an increase in the need for circulating capital, they finance the increase in circulating capital without concern. It is a dramatic error because an increase of the need for circulating capital means degeneration in the competitive battle. And as the competition becomes fiercer the probability of liquidating circulating capital decreases.

\section{Interlude: From the Sky to ...}

Please to meet you ... I am Einstein!

I spent all my life in exploring mysteries of the sky....

At the end of my life I went to the sky to check whether my ideas were right....

What a difference...from the sky imagined from the earth and... walking around the clouds, jumping from one star to another, falling down in a black hole riding the photon wind...

Believe me! The Sky is.....Well I can't find words to describe it... You have to personally experience the sky to be able to comprehend...

So God in His Supreme Benevolence (and due to the fact that when I go walking around the sky I ask so many questions that no one angel can stand me anymore) sent me to... put the Sky into your room ... follow me!

\section{From the theory to Governance methodologies}

Beyond the value life cycle there is a new dream: how to become younger.

Being more concrete, using Value Life Cycle I have developed three methodologies to Govern the strategic development of an enterprise through the Governance of its self-evolution process: 
- How to forecast the future capacity of producing Value at BU level.

- How to change the capacity of producing value at BU level

- How to design an autopoietic strategic plan ethically inspired and aesthetically superb

I will conclude with a generalization of these methodologies to any human system.

\section{How to forecast the}

future capacity of producing value at BU level.

Using the Value Life Cycle I developed a methodology to forecast the capability to produce value of an enterprise at BU level.

The methodology works in this way.

\section{$I^{\circ}$ Phase}

\section{Interview with the entrepreneur}

The aim of the interview is to have the entrepreneur describe his "view" of industry in terms of:

\section{Boundaries:}

- Types of Clients

○ Clients needs

- Geographic scope

- Product and process technologies

- Value chain

\section{Competitors}

○ Description

- Market shares

Main strategies in the industries. We mean the definition of a weighted mix of fundamental strategies (entrepreneurial creation, quality competition, efficiency competition, representation competition, surviving competition)

The interview is an ethnographic one! We do not need an objective description. We need the entrepreneur description. In fact, on the one hand, the expression 
"objective description" is epistemologically meaningless. On the other hand, the entrepreneur makes decisions, chooses strategies and so on, taking into account the description of the $\mathrm{BU}$ and of the related industry in His mind and not an objective description or a description which is in someone else's mind.

The interview reveals the cognitive system of the entrepreneur.

\section{Phase}

\section{Strategic metaphor of the present}

Using "the interview results, we can (through a specific algorithm we have developed) position the firm over a matrix which we have called "destiny matrix".

The dimensions of this matrix are:

Potential profitability of the industry where the considered BU competes. Potential profitability is calculated using the weighted mix of fundamental strategies. Roughly speaking the potential profitability measures the value that can be produced operating in that industry.

In other words, potential profitability measures the level of entrepreneurial innovation.

In spite of the fact that we live (and we declare to live) in a very fast changing world, firms have a lot of difficulties in looking over the present. In other words, firms prefer to compete inside present boundaries of the business than design new boundaries.

The result is that:

- Competition becomes fiercer and fiercer.

- The innovation comes from "garage competitors" (for example competitors like Apple when they almost destroyed IBM) who generate "catastrophic" change in the business.

The combined effect of increasing competition and the risk of revolutionary new comers make the probability of making money decrease.

Starting from main strategies of the firm, our algorithm determines at which level the decrease of the probability of making money has arrived. Level of entrepreneurial innovation can be expressed on a scale of 1 to 10 . 
Competitiveness of the BU. Whatever the level of entrepreneurial innovation might be, it is important to determine the strength of the firm against its competitors. Competitiveness is calculated using market shares of competitors in the industry

Level of competitive advantage can be expressed on a scale of 1 to 10 .

Different positions in the matrix are characterized by differences in capability to produce value: sales, EBITDA, cash-flow form sales.

We divided the destiny matrix into five main zones. Each of them is described through a metaphor.

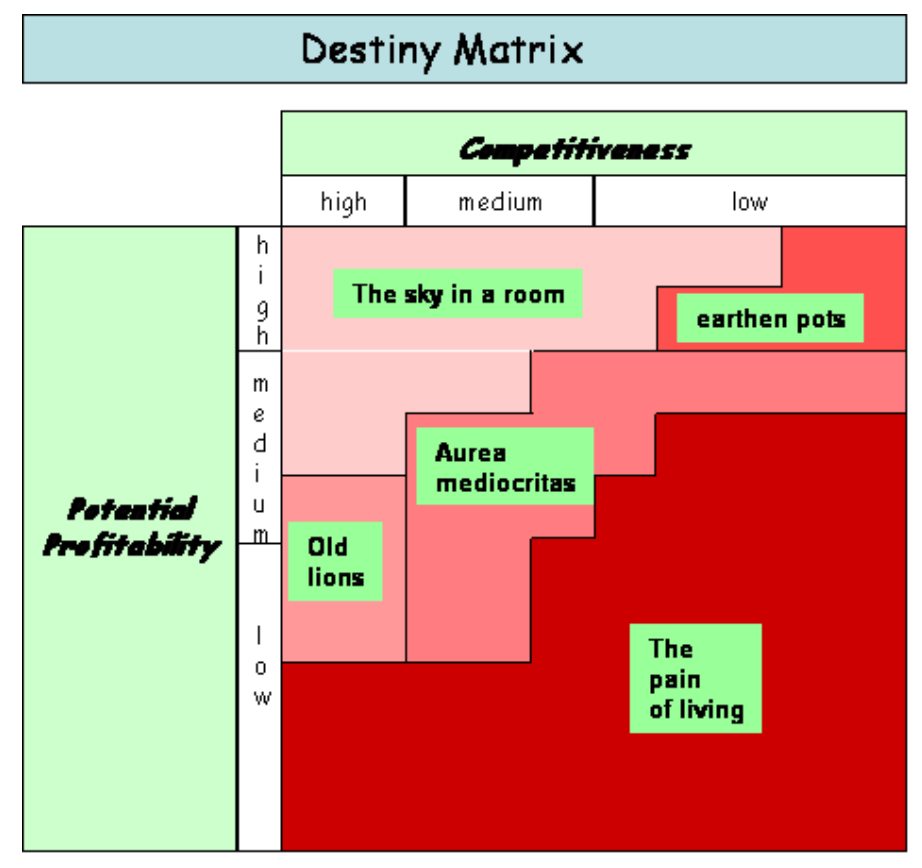

First area "The sky in a room" (the origin of the metaphor is a very poetic and popular Italian song from the sixties).

This area is characterized by a high value of both entrepreneurial innovation and competitive advantage.

Second area "The earthen pot". The metaphor comes from a novel of one of the most outstanding Italian writers: Alessandro Manzoni. He writes about a very 
unlucky pot which has been forced to make a not so enjoyable trip together with iron vases. This area is characterized by a high value of entrepreneurial innovation and a low value of competitive advantage.

Third area "The Old lions"

The lion is the king of the forest. However, when the lion gets old, its strength is only a memory of the past. This area is characterized by a medium to low value of entrepreneurial innovation and a high value of competitive advantage

Fourth area "Aurea mediocritas"

Aurea mediocritas is the expression the Latin Poet Orazio have used to describe a not so bad "middle" position (in a system). This area is characterized by a medium value of both entrepreneurial innovation and competitive advantage.

Fifth area "The Pain of living"

This area is characterized by a low value of both entrepreneurial innovation and competitive advantage.

\section{Phase}

\section{Strategic evolution}

From the position in the matrix we can calculate the path of evolution of strategic position of the BU over time.

And due to the fact that different points of the matrix are characterized by different values of sales, EBITDA, cash-flow from sales, we can also calculate the evolution paths for sales, EBITDA, cash-flow from sales.

\section{How to change the capacity of producing value at BU level} Using the Value Life Cycle it is possible to support an entrepreneur (or a managerial team) to redesign the identity of an enterprise not to compete; but to eliminate competition. In other words: I developed the first methodology to rebuild (instead of defending) the capability of producing value of an enterprise. Actually the ethnographic interview can become an autopoietic one. I mean an interview which stimulates a new capability of the entrepreneur to imagine new social dreams. 
In fact, the questions can be seen as a new language which enriches the cognitive system of the entrepreneur and it allows him (or her) to see a wider part of the environment. Above all: The Signs of Future Times. Becoming aware of new potentialities the entrepreneur desires to restart the Value life Cycle. Following different steps of the interview the entrepreneur becomes able to develop new dreams which are the catalyzers of new conversations. These conversations will generate new BUs and then, new industries with new attractiveness.

\section{How to design an autopoietic strategic plan ethically inspired and aesthetically superb}

Restarting Value Life Cycles of BUs is the core of the Strategic Management Process. Anyway a Strategic Plan should go far beyond.

To design a complete Strategic Plan I developed a model of an ideal Strategic Plan. The model for interviewing the entrepreneur is part of it.

The model is represented in the following figure.

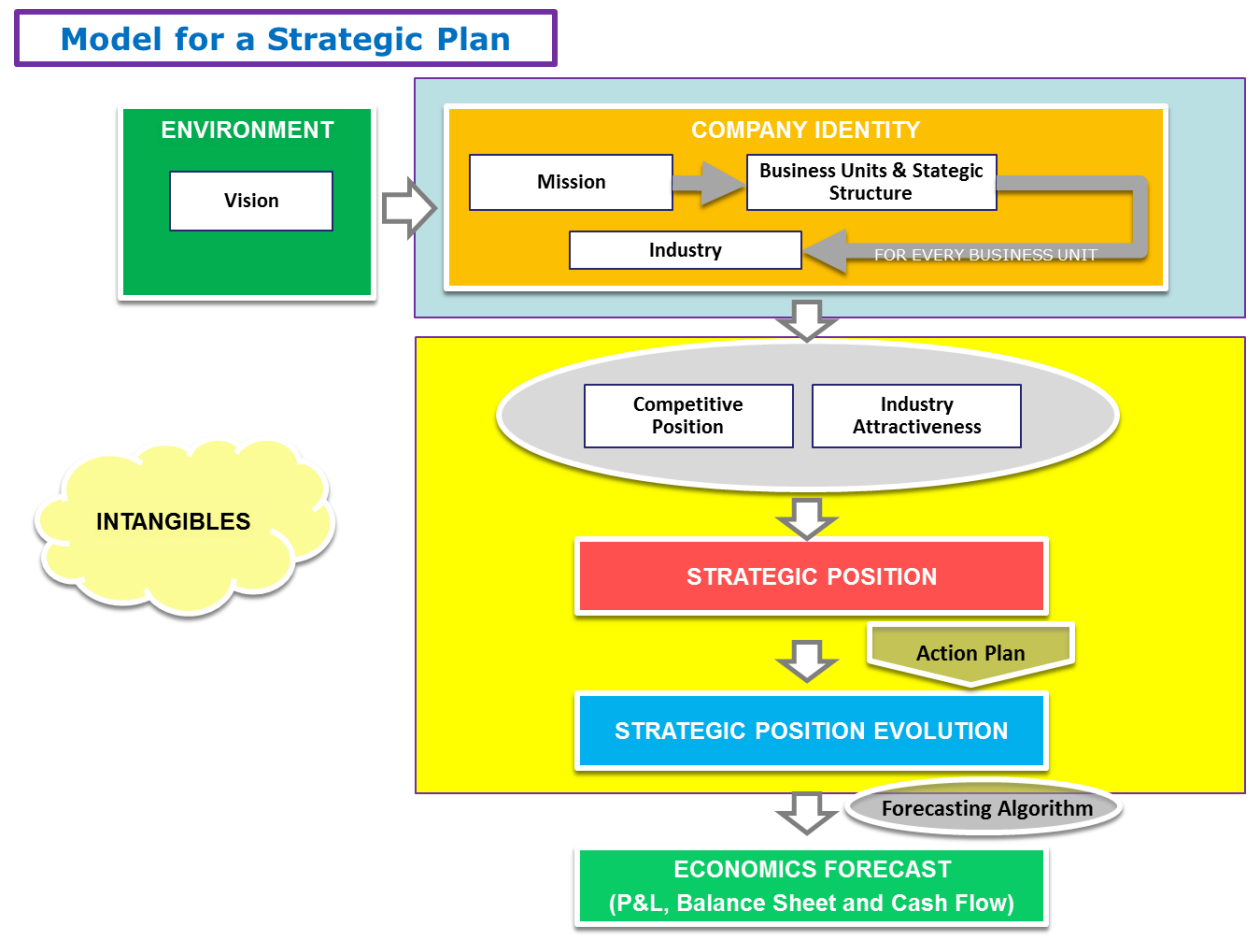


Form a systemic point of view, this is a more general cognitive system which is useful for top managers of big corporations.

Nowadays, the cognitive system of top managers make them consider big Corporations as Institutions. It doesn't matter whether big Corporations produce economic value or not. Big Corporations have a social role that has to be conserved.

Actually, this is an "hidden ideology": no one explicitly proclaims it. Anyway, it shines through Strategic Plans which are nothing but bureaucratic budgets.

To overcome come this two faced situation, it is enough to make top managers of big Corporation use the model of a Strategic Plan that I have developed. Using this model no one could simply wright down a yearly budget.

\section{Conclusions: generalizing ...}

The main characteristic of a human systems is the capacity of an autonomous evolution which repeats, recursively, the "module" previously described. Unfortunately, if not managed, this evolution progressively isolates (cognitively) the system from the environment and the meaning of the human system becomes unintelligible by the environment. Maturana and Varela talk about structural coupling. Consequently the environment loses its interest to the system and stops the exchange of matter and energy. The final result is the death of the system.

To avoid this fatal exit of the autonomous evolution process, this autonomous evolution process has to be managed. In which way?

Generalizing what I have said about enterprise, the role of the person who governs a human system has to change. The "governor" (the entrepreneur) has to continuously change his (or her) cognitive system and cognitive resources available of all the actors "living" in the system use.

In this way conversations can continuously exploit Signs of the Future Times instead of always becoming narrower and narrower.

\section{Bibliography}

C.BILTON, S.CUMMINGS, Creative Strategy: Reconnecting Business and Innovation, Wiley \& Sons, Chichester 2010. 
M.BLASONE, P.JIZBA, G.VITIELLO, Quantum Field Theory and Its Macroscopic Manifestations, Imperial College Press, London, 2011.

D.BOHM, B.J.HILEY, The Undivided Universe, Routledge, New York, NY, 1993.

S.CUMMINGS, D.WILSON, Images of Strategy, Blackwell Publishing, Malden, MA, 2003.

G. S.DAY, D. J.REIBSTEIN, R. E.GUNTHER, Wharton On Dynamic Competitive Strategy, John Wiley, New York, NY, 1997.

A.F.DE TONI, A.BARBARO, Visione Evolutiva, Etas Libri, Milano 2010.

E.DEL GIUDICE, 2010, Una via quantistica alla teoria dei sistemi, in Ulivi, L. (Ed.), Strutture Di Mondo II Pensiero Sistemico Come Specchio Di Una Realtà Complessa, II Mulino, Bologna, Mondo, 2010. pp. 47-70.

E.FREEMAN, A Stakeholder Approach to Strategic Management, Pitman, London, 2001.

D. FOGG, Team-Based Strategic Planning, CreateSpace, Charleston, SC, 2010.

A.GODINO, R.CANESTRARI, La psicologia scientifica: nuovo trattato di psicologia generale, CLUEB Bologna, 2007.

A.C.HAX, N.S.MAJLUF, Direzione strategica (Strategic management), IPSOA, Milano, 1998.

A.S.HUFF (ed.), Mapping Strategic Thought, New York, NY, John Wiley, 1990.

I.LICATA, Osservando La Sfinge - La Realtà Virtuale Della Fisica Quantistica, Di Renzo, Arcobaleno, 2003.

I.LICATA, G.MINATI, "Creativity as cognitive design - the case of mesoscopic variables in meta-structures", in Columbus, F. (Ed.), Creativity: Fostering, Measuring and Contexts, Nova Publishers, New York, NY, 2010, pp. 95-107.

N.LUHMANN, Organizzazione e Decisione, Bruno Mondadori, Roma, 2005.

H.R.MATURAMA, F.J.VARELA, The Tree of Knowledge, Shambhala Publications, Boston, MA 1998.

G.MINATI, The meta-structures project, (online), ArXiv, 2009 available at: http://arxiv.org/ftp/ arxiv/papers/0903/0903.0592.pdf (accessed May 2011).

G.MINATI, M.ABRAM, E.PESSA, Processes of Emergence of Systems and Systemic Designing Properties, World Scientific, Singapore 2009.

H.MINTZBERG, The Rise and Fall of Strategic Planning, Free Press, New York, NY, 1994.

H.MINTZBERG, B.AHLSTRAND, e J.LAMPLE, Strategy Safari, Free Press, New York, NY, 1998.

J.E.MOORE, The death of competition: leadership and strategy in the age of Business ecosystems, John Wiley, New York, NY, 1996.

E.PESSA, On models of emergent metastructures, in G.MINATI, M.ABRAM, E.PESSA (Eds), Methods, Models, Simulations And Approaches Towards A General Theory of Change, World Scientific, Singapore, 2011 pp. 113-34.

A.PETTIGREW, R.WHITTINGTON, Handbook of Strategy and Management, Sage Publications, London, 2002.

M.SVITEK, Quantum System Theory: Principles and Applications, VDM Verlag Dr. Müller, Saarbrücken, 2010.

F.ZANOTTI, Un Expo della Conoscenza per fare emergere una nuova Società, Edizioni CSE-Crescendo, Milano, 2010. 
F.ZANOTTI, La Strategia Come Processo di Creazione Sociale, (forthcoming) 2013. Strategia aziendale - Strategia aziendale vol.7, UTET UNIVERSITA, Torino, 1998 (a cura di V.CODA, G.INVERNIZZI, M.RISPOLI).

Strutture di mondo. II pensiero sistemico come specchio della realtà complessa, II Mulino, Bologna, 2010 (a cura di L. Urbani Ulivi). 
